\title{
Vitamin D Status in Children with Tuberculosis
}

\author{
Ira Shah $^{1} \cdot$ Drishti Tolani $^{1} \cdot$ Neha Bansal $^{1} \cdot$ Naman S. Shetty $^{1}$ (D)
}

Received: 20 June 2019 / Accepted: 8 July 2019 / Published online: 23 July 2019

(C) Dr. K C Chaudhuri Foundation 2019

To the Editor: Epidemiological evidence supporting the function of vitamin $\mathrm{D}$ in the immune response to tuberculosis (TB) infection is being increasingly reported [1]. Thus, vitamin $\mathrm{D}$ deficiency is being considered as a risk factor for tuberculosis.

This retrospective analysis was done at the Pediatric TB clinic in a tertiary children hospital. Forty-two patients of 242 patients referred to the TB clinic from 2010 to 2011 and were included in the study. Their serum 25 -hydroxyvitamin D [25- $(\mathrm{OH}) \mathrm{D}]$ levels, the type of tuberculosis that they were diagnosed with and the month of testing after antitubercular therapy (ATT) initiation were recorded. 25-hydroxyvitamin D levels were recorded as sufficient, insufficient and deficient if greater than $30 \mathrm{ng} / \mathrm{ml}$, between 11 and $30 \mathrm{ng} / \mathrm{ml}$ and less than $11 \mathrm{ng} / \mathrm{ml}$ respectively [2].

The association between vitamin D levels and age, gender, type of tuberculosis, month of testing after initiating ATT was analyzed by Chi-Square test or Fishers exact test or unpaired $\mathrm{T}$ test and were statistically insignificant when statistical significance was considered if the $p$ value was $<0.05$. $P$ values for the association of vitamin D levels with age, gender and month of testing after initiating ATT were $0.98,0.09$ and 0.55 respectively.

High, deficient, insufficient and sufficient 25-(OH) D levels were seen in 1(2.3\%), 11(26.8\%), 24(58.5\%) and $6(14.6 \%)$ patients respectively. Pulmonary TB, abdominal $\mathrm{TB}$, bone TB, latent TB, disseminated TB, TB adenopathy, neuro TB and serositis was present in 23 patients (55\%), 3 patients (7\%), 4 patients (9\%), 5 patients (12\%), 2 patients (5\%), 2 patients (5\%), 2 patients (5\%) and 1 patient (2\%) respectively. $25-(\mathrm{OH}) \mathrm{D}$ testing was done before initiating ATT, during intensive phase of ATT and maintenance phase

Ira Shah

irashah@pediatriconcall.com

1 Pediatric TB Clinic, B. J. Wadia Hospital for Children, Acharya Donde Marg, Parel, Mumbai 400012, India of ATT in 10(23.8\%), 17(40.5\%) and 15 patients (35.7\%) respectively.

In our study $85.3 \%$ of patients were found to have either insufficiency or deficiency of vitamin D which is highly consistent with a similar study carried out in England [3]. In our study only 6 patients had sufficient vitamin D levels.

Studies have established hypothetical reasons for the association of vitamin D deficiency and tuberculosis which include decreased dietary intake or increased utilization to combat the infection [4].

Children have a lesser developed immune system and are more prone to TB and children below $5 \mathrm{y}$ of age have greater severity of tuberculosis as compared to others [5]. Thus, more studies to establish the benefits of vitamin D supplementation in children with tuberculosis is particularly required.

\section{Compliance with Ethical Standards}

Conflict of Interest None.

\section{References}

1. Nnoaham KE, Clarke A. Low serum vitamin D levels and tuberculosis: a systematic review and meta-analysis. Int $\mathrm{J}$ Epidemiol. 2008;37:113-9.

2. Misra M, Pacaud D, Petryk A, Collett-Solberg PF, Kappy M. Drug and therapeutics committee of the Lawson Wilkins pediatric endocrine society. Vitamin D deficiency in children and its management: review of current knowledge and recommendations. Pediatrics. 2008;122:398-417.

3. Williams B, Williams AJ, Anderson ST. Vitamin D deficiency and insufficiency in children with tuberculosis. Pediatr Infect Dis J. 2008;27:941-2.

4. Syafii AZ, Sukadi A, Setiabudiawan B. Association between serum vitamin D level and tuberculosis in children. Paediatr Indones. 2008;48:350-3.

5. Moyo S, Verver S, Mahomed H, et al. Age-related tuberculosis incidence and severity in children under $5 \mathrm{y}$ of age in Cape Town, South Africa. Int J Tuberc Lung Dis. 2010;14:149-54.

Publisher's Note Springer Nature remains neutral with regard to jurisdictional claims in published maps and institutional affiliations. 